\title{
RBM38 is involved in TGF- $\beta$-induced epithelial-to-mesenchymal transition by stabilising zonula occludens-1 mRNA in breast cancer
}

\author{
Jing $\mathrm{Wu}^{1,3}, \mathrm{Xu}$-Jie Zhou ${ }^{1,3}, \mathrm{Xi}$ Sun ${ }^{1,3}$, Tian-Song Xia ${ }^{1}$, Xiao-Xia Li ${ }^{1}$, Liang Shi ${ }^{1}$, Lei Zhu ${ }^{1}$, Wen-Bin Zhou ${ }^{1}$, \\ Ji-Fu Wei ${ }^{\star, 2}$ and Qiang Ding ${ }^{\star, 1}$ \\ ${ }^{1}$ Jiangsu Breast Disease Center, The First Affiliated Hospital with Nanjing Medical University, 300 Guangzhou Road, Nanjing \\ 210029, China and ${ }^{2}$ Research Division of Clinical Pharmacology, The First Affiliated Hospital with Nanjing Medical University, \\ 300 Guangzhou Road, Nanjing 210029, China
}

Background: The transforming growth factor- $\beta$ (TGF- $\beta$ ) pathway plays a vital role in driving cancer cell epithelial-mesenchymal transition (EMT). Zonula occludens-1 (ZO-1), which is downregulated in response to TGF- $\beta$, is able to control endothelial cell-cell tension, cell migration, and barrier formation. However, the molecular mechanism of how TGF- $\beta$ regulates ZO-1 expression remains unclear.

Methods: Breast cancer cells were treated with TGF- $\beta$ to induce an EMT progress. Chromatin immunoprecipitation and dualluciferase reporter assay were performed to investigate direct relationship between Snail and RNA binding motif protein 38 (RBM38). The RNA immunoprecipitation combined with RNA electrophoretic mobility shift assay and dual-luciferase reporter assay were conducted to testify direct relationship between RBM38 and ZO-1. The ZO-1 siRNA was transfected to breast cancer cells that overexpress RBM38 and the control, followed by transwell and Matrigel invasion assays to examine cell migratory and invasive ability.

Results: Transforming growth factor- $\beta$ induced a remarkable downregulation of RBM38 in breast cancer that was directly regulated by transcription repressor Snail targeting the E-box elements in promoter region of RBM38 gene. Additionally, RBM38 positively regulated ZO-1 transcript via directly binding to AU/U-rich elements in its mRNA $3^{\prime}-$ UTR. Moreover, by magnifying RBM38 expression, cell migration and invasion mediated by knockdown of ZO-1 in breast cancer were reversed.

Conclusions: All the results clarified a linear regulation relationship among Snail, RBM38, and ZO-1, implicating RBM38 as a pivotal mediator in TGF- $\beta$-induced EMT in breast cancer.

Breast cancer is the most common malignancy in females worldwide (Chen et al, 2016; Siegel et al, 2016), and the metastasis accounts for the majority of deaths from breast cancer. One potential mechanism for invasion and metastasis in breast cancer is due to the occurring of epithelial-mesenchymal transition (EMT) that allows the polarised epithelial cells to assume elevated migratory capacity, invasiveness, enhanced resistance to apoptosis, and stem cell properties (Kalluri and Weinberg, 2009; Thiery et al,

\footnotetext{
*Correspondence: Dr Q Ding; E-mail: dingqiang@njmu.edu.cn or Dr J-F Wei; E-mail: weijifu@hotmail.com

${ }^{3}$ These authors contributed equally to this work.
}

Received 20 January 2017; revised 31 May 2017; accepted 7 June 2017; published online 6 July 2017

(C) 2017 Cancer Research UK. All rights reserved 0007-0920/17 
2009). Though recent studies suggest that EMT may be dispensable for the carcinoma metastatic cascade (Fischer et al, 2015; Zheng et al, 2015), it is still not ruled out as a driver of cancer progression for its pivotal role in helping epithelial cancer cells to invade ( $\mathrm{Li}$ and Kang, 2016; Nieto et al, 2016).

The first steps of EMT are the disassembly of epithelial cell-cell contacts. Epithelial cells associate with each other through laterally located, specialised cell-cell contact structures including tight junctions (TJ), adherens junctions (AJ), desmosomes, and gap junctions (Xu et al, 2009; Lamouille et al, 2014). Zonula occludens1 (ZO-1, also known as tight junction protein 1) is a critical regulator of $\mathrm{TJ}$ assembly that regulates $\mathrm{AJ}$ function by coordinating the assembly or dynamics of the cortical cytoskeleton (Fanning and Anderson, 2009).

The EMT is triggered by multiple extracellular signals, including components of the extracellular matrix like collagen and hyaluronic acid, soluble growth factors such as transforming growth factor- $\beta$ (TGF- $\beta$ ), fibroblast growth factor (FGF), and epidermal growth factor (EGF) (Thiery and Sleeman, 2006). Transforming growth factor- $\beta$ is one of the best known inducer of EMT. Elevated levels of TGF- $\beta$ in malignant mammary cells enhance breast cancer invasion, migration, and evasion of immunity. Each of these functions plays a vital role in tumour progression and eventually takes part in the metastatic process (Padua and Massague, 2009). In response to TGF- $\beta$, the type II TGF- $\beta$ receptor phosphorylate the type-I TGF- $\beta$ receptor, which then initiates downstream signalling through either Smadmediated canonical signalling or Smad-independent noncanonical signalling (Shi and Massague, 2003). Via interaction with Smad complex, multiple transcription factors are initiated so as to induce EMT. It is widely testified that TGF- $\beta$ induced a phenotypic change with decreased expression of epithelial markers E-cadherin and ZO-1 (Miettinen et al, 1994; Tian and Phillips, 2002) that belong to $\mathrm{AJ}$ and $\mathrm{TJ}$, respectively. Unlike the well-illustrated mechanism of E-cadherin regulated by TGF- $\beta$ (Takano et al, 2007; Fransvea et al, 2008; Yu et al, 2015), it still needs much effort to uncover how TGF- $\beta$ affects the expression of ZO- 1 .

RNA binding proteins (RBPs) regulate mRNA splicing, export, stability, or translation mainly by the interaction with a particular sequence of target gene mRNA (Yan et al, 2012), and multiple mRNAs are co-mediated by one or more sequence-specific RBPs (Keene, 2007). Previous studies showed that ZO-1 mRNA 3'untranslated regions ( $3^{\prime}$-UTRs) readily associated with cytoplasmic RBPs including auxin upregulated F-box protein 1 (AUF1) (Chen et al, 2008), human antigen R (HuR) (Yu et al, 2011), and TIA-1related protein (TIAR) (Xiao and Wang, 2014; Yang et al, 2014). Previously, our group found that the RNA binding motif protein 38 (RBM38, also called RNPC1), a tumour suppressor in breast cancer, participated in the EMT process (Xue et al, 2014). Meanwhile, it regulated expression of various target genes through binding to AU/U-rich elements (AREs) in their mRNA $3^{\prime}$-UTR (Cho et al, 2012; Xu et al, 2013; Shi et al, 2015).

In breast cancer, reduction of $\mathrm{ZO}-1$ level is correlated with decreased tumour differentiation and poor prognosis (Itoh and Bissell, 2003; Martin et al, 2004). The ZO-1 possesses several AREs in its mRNA $3^{\prime}$-UTR, presenting as a potential target of RBM38. Furthermore, the promoter region of RBM38 gene contains several E-box DNA sequences ( $5^{\prime}$-CANNTG- $\left.3^{\prime}\right)$ that can be recognised by Snail (Batlle et al, 2000; Park et al, 2012), a prominent mediator of TGF- $\beta$-induced EMT that displays a broad spectrum of biological functions in tumour progression, including cancer metastasis, drug resistance, and tumour recurrence (Wang et al, 2013). Snail, together with Slug and less explored Smuc, pertains to the Snail family. Although the three members all encode transcription factors of the zinc-finger type and bind to the E-box elements, Snail displays a higher affinity with the target sequences (Nieto, 2002; Bolos et al, 2003). Here we put forward the hypothesis that TGF- $\beta$ promoted Snail expression that then acts as a transcriptional repressor on RBM38 expression. Additionally, decreased RBM38 level mediated ZO-1 post-transcriptional regulation, thus forming a new pathway that delivered the signals from TGF- $\beta$ to ZO- 1 and eventually modulated EMT progression.

\section{MATERIALS AND METHODS}

Cell culture. The human breast cancer cell lines, MCF7, BT474, and MDA-MB-231, were obtained from the American Tissue Culture Collection (ATCC, Manassas, VA, USA). For TGF- $\beta$ treatment, MCF7 and BT474 cells were exposed to $10 \mathrm{ng} \mathrm{ml}^{-1}$ of TGF- $\beta 1$ (PeproTech, Rocky Hill, NJ, USA) over different time points (1-5 days). Cells were then harvested for protein or gene expression analysis. For experiments using inhibitor, MCF7 and BT474 cells were pretreated with $10 \mu \mathrm{M}$ of SB431542 (Selleckchem, Houston, TX, USA) (Taipaleenmaki et al, 2012), a specific inhibitor of TGF- $\beta$ type I receptor, for $30 \mathrm{~min}$ and then stimulated with TGF- $\beta 1$ (10 $\left.\mathrm{ng} \mathrm{ml}^{-1}\right)$ for $72 \mathrm{~h}$.

Lentivirus transfection. Lentivirus constructs of RBM38 overexpression and knockdown were obtained from GenePharma (Shanghai, China) and generated as in our previous study (Shi et al, 2015). Briefly, cells were plated in 6-well dishes at 30-40\% confluence and infected with the retroviruses. Stable pooled populations of breast cancer cells were generated by selection using puromycin $\left(3 \mu \mathrm{g} \mathrm{ml}^{-1}\right)$ for 14 days.

Small interfering RNA (siRNA) and plasmid transfection. The expression vectors encoding wild-type $\mathrm{ZO}-1$ were constructed as described previously (Brysse et al, 2012). Plasmids and siRNAs (GenePharma) and were transfected into breast cancer cells using Lipofectamine 3000 (Invitrogen Co., Carlsbad, CA, USA) according to the manufacturer's instructions. The cells were cultured in a 6-well plate for 24 to $48 \mathrm{~h}$ and the expression level was detected by western blot and qRT-PCR to determine the interference efficiency.

For TGF- $\beta$ treatment, the medium was supplemented with TGF- $\beta 1\left(10 \mathrm{ng} \mathrm{ml}^{-1}\right)$ for another $72 \mathrm{~h}$ before siRNA transfection.

Western blot analysis. Cells were lysed and analysed by western blotting as described previously (Shi et al, 2015). The primary antibodies were used as follows: anti-rabbit RBM38 (Santa Cruz Biotechnology, Dallas, TX, USA), ZO-1, Snail (Cell Signaling Technology, Danvers, MA, USA), anti-mouse $\beta$-actin (Cell Signaling Technology). The anti-rabbit and anti-mouse secondary antibodies were from Cell Signaling Technology. The antibodies were diluted according to the manufacturer's instructions.

Chromatin immunoprecipitation assay (ChIP). The ChIP assay was performed by chromatin immunoprecipitation kit (17-371, EZ-ChIP, Millipore, Bedford, MA, USA) according to the manufacturer's instructions. Briefly, MDA-MB-231 and MCF7 cells (with or without TGF- $\beta$ stimulation) were plated in $15 \mathrm{~mm}$ culture dishes, the proteins were crosslinked with DNA by $37 \%$ formaldehyde, and then stopped by adding $10 \times$ glycine solution. Sonication of cell lysate was performed with the condition of 200 cycles/burst, 5.0 duty factor at 70.0 peak power (Covaris S220, Woburn, MA, USA) to shear the chromatin to an average size of $500 \mathrm{bp}$. The supernatant fractions were diluted and incubated with protein $\mathrm{G}$ agarose for $1 \mathrm{~h}$ at $4{ }^{\circ} \mathrm{C}$. As Input, $10 \mu \mathrm{l}(1 \%)$ of the supernatants was preserved. Then, protein $\mathrm{G}$ agarose was pelleted and supernatants were reincubated with $5 \mu \mathrm{g}$ primary antibody: anti-Snail (Santa Cruz Biotechnology) or normal mouse IgG, at $4{ }^{\circ} \mathrm{C}$ overnight with rotation. After this, the supernatants were reincubated with protein $\mathrm{G}$ agarose for $1 \mathrm{~h}$ at $4{ }^{\circ} \mathrm{C}$. After washing the beads, the protein/DNA complexes were eluted twice. Crosslink was reversed by adding $5 \mathrm{M} \mathrm{NaCl}$ and incubation at $65^{\circ} \mathrm{C}$ 
overnight. The immunoprecipitated DNAs were purified by treatment with RNase A and proteinase $\mathrm{K}$ as well as the Input. Purified DNA was evaluated and analysed by PCR with specific primers listed in the Supplementary Table 1.

Luciferase reporter assay. Luciferase reporter assay was performed with the Dual-Luciferase Reporter Assay System (E1910, Promega, Madison, WI, USA). Briefly, $5 \mathrm{ng}$ of Renilla luciferase vector (pRL-TK; Promega), an internal control, and $200 \mathrm{ng}$ of a pGL3 reporter that contained various target regions were cotransfected into breast cancer cells. At $48 \mathrm{~h}$ after transfection, cells were harvested to measure the luciferase activity.

RNA isolation, reverse transcription, and qRT-PCR. Total RNA was isolated using Trizol reagent (TaKaRa, Kusatsu, Japan), and cDNA synthesis was performed using Primescript RT Reagent (TaKaRa) according to the manufacturer's instructions. The qRTPCR was performed using FastStart Universal SYBR Green Master (Roche, Reinach, Switzerland) and then conducted using a StepOnePlus Real-Time PCR system (Applied Biosystems, Foster City, CA, USA), and the abundance of target mRNAs was normalised based on $\beta$-actin. The primers used here are listed in Supplementary Table 2 of Supplementary Material.

Immunohistochemical (IHC) staining and analysis. The breast cancer sample tissue microarrays (BC08118) for IHC analysis were purchased from Biomax (Rockville, MD, USA). The same tissue samples were stained with RBM38 and ZO-1 antibody respectively. The RBM38 antibody (LifeSpan Biosciences, Seattle, WA, USA) was used at the dilution of $1: 300$. The ZO-1 antibody (Abcam, Cambridge, MA, USA) was used with a concentration of $10 \mu \mathrm{g} \mathrm{ml}^{-1}$. The IHC staining was conducted and analysed as previously described (Shi et al, 2015).

Immunofluorescence (IF). Immunofluorescence assay was performed as described previously (Lou et al, 2017). Primary antibodies were used as follows: RBM38 (Santa Cruz Biotechnology) and ZO-1 (Abcam). The FITC-conjugated secondary antirabbit antibody (Jackson ImmunoResearch, West Grove, PA, USA) and Alexa 594-conjugated secondary anti-goat antibody (Jackson ImmunoResearch) were applied. The nuclei were stained with 4,6diamidino-2-phenylindole (DAPI).

RNA immunoprecipitation (RIP). RNA immunoprecipitation was carried out as previously described (Shi et al, 2015). The cytosolic extract from MCF7 cells was prepared with RNA immunoprecipitation lysis buffer (Millipore), and then incubated with $5 \mu \mathrm{g}$ of anti-RBM38 (Santa Cruz Biotechnology) or nonimmunised rabbit $\operatorname{IgG}$ at $4{ }^{\circ} \mathrm{C}$ overnight. The mRNA-protein immunocomplexes were brought down by protein $A / G$ magnetic beads, followed by RT-PCR and qRT-PCR analysis.

Recombinant protein purification and RNA probes. The recombinant RBM38 proteins were expressed and purified as described previously (Lou et al, 2017). To generate RNA electrophoretic mobility shift assay (REMSA) probes, various regions (A-D) in ZO-1 mRNA $3^{\prime}$-UTR were amplified by PCR with T7 promoter sequence ( $5^{\prime}$-TAATACGACTCACTATAGGG$\left.3^{\prime}\right)$. The primers for probes A-D are listed in Supplementary Material Table 3. Biolabelled RNA probes were made from in vitro transcription with a MEGA shortscript Kit (Ambion, Waltham, MA, USA) in the presence of biotin-16-UTP (Roche) according to the manufacturer's instructions.

RNA electrophoretic mobility shift assay. The REMSA was performed with a LightShift Chemiluminescent RNA EMSA Kit (Thermo, Waltham, MA, USA) following the manufacturer's instruction. Briefly, $4 \mathrm{mg} \mathrm{ml}^{-1} \mathrm{RBM} 38$ and $2 \mathrm{nM}$ biotin-labelled RNA probe were mixed in a REMSA binding buffer $(10 \mathrm{mM}$ HEPES (pH 7.3), $20 \mathrm{mM} \mathrm{KCl,} 1 \mathrm{mM} \mathrm{MgCl} 2,1 \mathrm{mM}$ dithiothreitol) and incubated for $30 \mathrm{~min}$ at room temperature. To prevent nonspecific binding, $10 \mathrm{mg} \mathrm{ml}^{-1}$ of tRNA was added in the reaction system. The RNA/protein complexes were then electrophoreticed by $4 \%$ native polyacrylamide gel and transferred to nylon membrane (Thermo). The RNA was crosslinked with a UV lamp at a distance of $0.5 \mathrm{~cm}$ from the membrane for $3 \mathrm{~min}$. The membrane was blocked in blocking buffer for $15 \mathrm{~min}$ and then replaced for the blocking buffer with conjugate/blocking buffer (stabilised streptavidin-horseradish peroxidase conjugate $1: 300$ dilution). After washing with $1 \times$ wash buffer for 3 times, the membrane was incubated in substrate equilibration buffer for $5 \mathrm{~min}$. Then, the membrane was incubated in substrate working solution for $5 \mathrm{~min}$ and exposed.

Cell migration and invasion assay. Cell invasiveness was conducted using 24-well transwell inserts (Millicell Hanging Cell Culture Insert, PET $8 \mu \mathrm{m}$, Billerica, MA, USA) coated with $50 \mu \mathrm{l}$ of Matrigel ( $1 \mathrm{mg} \mathrm{ml}^{-1}$; BD Biosciences, Franklin Lakes, NJ, USA). Inserts were seeded with $5 \times 10^{4}$ cells in $200 \mu \mathrm{l}$ DMEM supplemented with $0.1 \%$ FBS, and $500 \mu \mathrm{l}$ of medium with $10 \%$ FBS was added to the lower chamber. Cell migration assay was carried out without the Matrigel. Cells were incubated at $37^{\circ} \mathrm{C}$ for $36 \mathrm{~h}$, after which noninvading cells were wiped from the upper side of the membrane. The number of invading or migrating cells was counted under the microscope in five independent fields and the average number of cells per field was represented in the graphs.

Statistical analysis. All experiments were repeated in triplicate, unless otherwise specified. The data were analysed using the SPSS 20.0 software (Chicago, IL, USA). The $\chi^{2}$ test was used to assess the correlation between RBM38 and the clinicopathological parameters. For all the continuous variables, Student's $t$-test was used to analyse the statistical significance of the differences between groups, and $P<0.05$ was considered to indicate a statistical significance.

\section{RESULTS}

Repression of RBM38 expression during TGF- $\beta$-induced EMT in breast cancer. To explore the alteration of RBM38 expression during TGF- $\beta$-induced EMT, MCF7 and BT474 cells were cultured in the absence or presence of TGF- $\beta$ over 5 days and monitored for a phenotypic switch (Figure 1A). The EMT induction was confirmed by the activation of Smad3, Snail, Slug, as well as the reduction of ZO-1 in protein level (Figure 1B). Notably, RBM38 expression showed a significant decrease in response to TGF- $\beta$ (Figure 1B). The reduction of RBM38 level was also observed in BT474 cells when treated with TGF- $\beta$ to induce EMT (Figure 1C). The expression of an activated version of the TGF- $\beta$ type I receptor could be inhibited via the potent and selective chemical inhibitor (i.e., SB431542) that blocks EMT and promotes an enhanced epithelial phenotype in cell culture (Xu et al, 2009). We blocked TGF- $\beta$ signalling by SB431542 that evidently inhibited downregulation of RBM38 protein levels (Figure $1 \mathrm{D}$ and E) by TGF- $\beta$. These data demonstrated that RBM38 expression was markedly reduced in breast cancer cells undergoing EMT and functioned as a mediator in TGF- $\beta$ signalling pathway.

Snail caused reduction of RBM38 levels in breast cancer. We transfected MDA-MB-231, a cell line that relatively expressed Snail highly (Dong et al, 2012), with small interfering RNAs (siRNAs) targeting Snail. It was found that RBM38 expression was evidently increased by knockdown of Snail at protein and mRNA levels $(P<0.05$; Figure 2A). The reduction of RBM38 in MCF7 cells that were treated with TGF- $\beta$ was also restrained with Snail knockdown $(P<0.05$; Figure $2 \mathrm{~B})$, whereas the phenomenon was not observed in MCF7 cells with Slug knockdown (Supplementary Figure S1A and $1 \mathrm{~B}$ ). 
A TGF- $\beta 1$
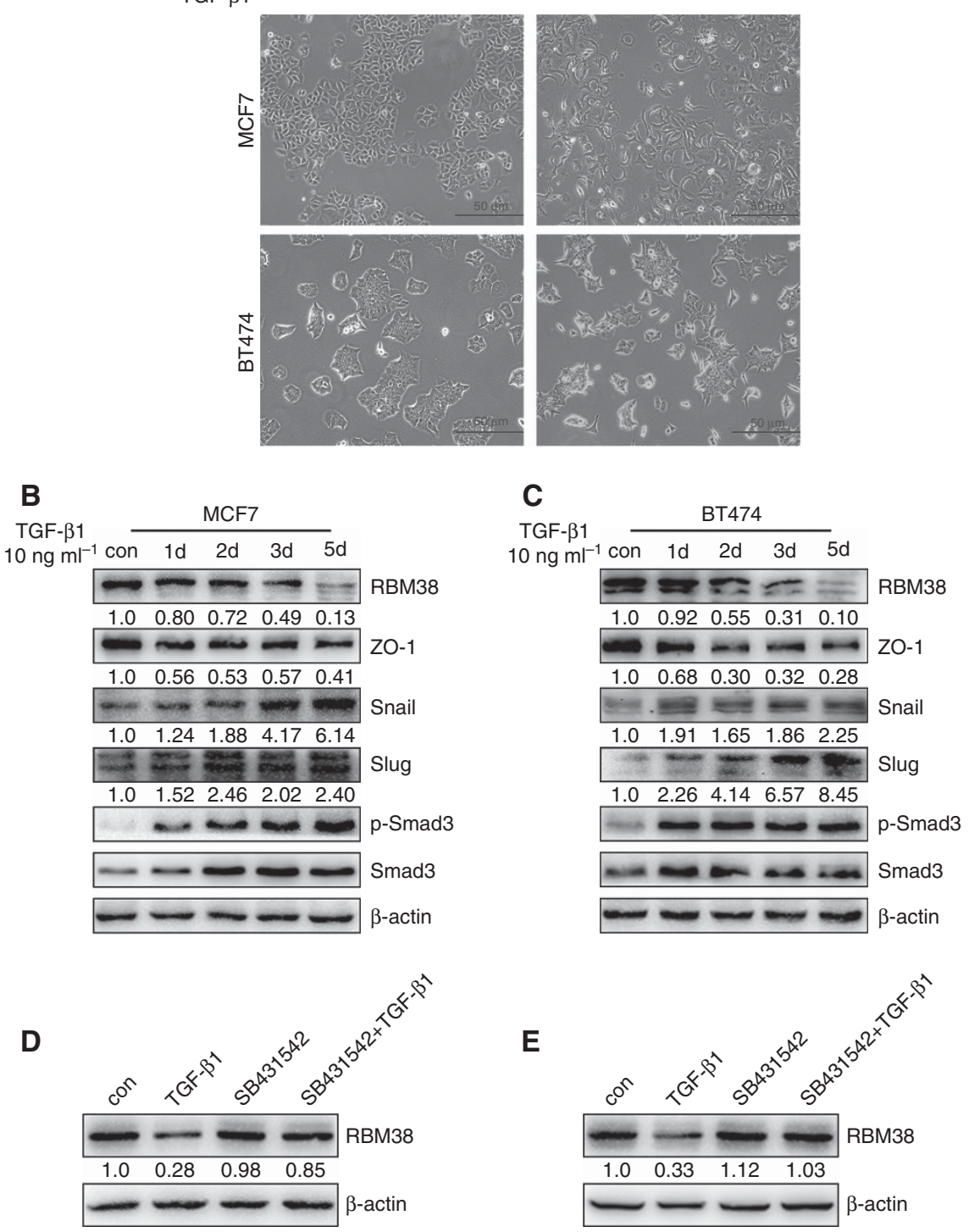

Figure 1. The RBM38 expression decreased during TGF- $\beta$-induced EMT. (A) Morphological contrast photos of MCF7 and BT474 cells treated without or with TGF- $\beta 1\left(10 \mathrm{ng} \mathrm{ml}^{-1}\right)$ for 5 days. Cells showed a more mesenchymal morphology than that in the absence of TGF- $\beta$. Scale bars indicated $50 \mu \mathrm{m}$. (B) The MCF7 cells and (C) BT474 cells were exposed to TGF- $\beta 1\left(10 \mathrm{ng} \mathrm{ml}^{-1}\right)$ for $0,1,2,3$, and 5 days. The EMT progress was confirmed by monitoring ZO-1, Snail, Slug, and p-Smad3 expression. Meanwhile, expression of RBM38 was remarkably reduced. (D) The MCF7 and (E) BT474 cells were cultured without (con) or with TGF- $\beta 1\left(10 \mathrm{ng} \mathrm{ml}^{-1}\right)$ followed by the addition of selective inhibitor SB431542 (10 $\left.\mu \mathrm{M}\right)$. After $72 \mathrm{~h}$ of treatment, the reduction of RBM38 expression induced by TGF- $\beta$ was restored by the addition of SB431542.

Snail repressed RBM38 expression via directly targeting E-box elements in the promoter of RBM38 gene. Then, we noticed that the RBM38 promoter region contained six Snail-binding E-boxes $\left(5^{\prime}\right.$-CANNTG- $\left.3^{\prime}\right)$. A ChIP assay was performed by using three sets of primers each containing two E-box elements (Figure 2C). Snail showed a stronger ability to associate with E-box- 1 and E-box- 2 in the promoter region of RBM38 gene in MCF7 cells that had undergone TGF- $\beta$-mediated EMT (Figure 2D). Additionally, endogenous Snail bound to the same region of RBM38 promoter in MDA-MB-231 cells (Figure 2E). We next cloned two RBM38 promoter-luciferase constructs, I ( -1880 to -1672$)$ and II $(-1221$ to -1028), based on the location of E-box-1 and E-box-2 (Figure 2F). With Snail knockdown in TGF- $\beta$-treated MCF7 cells, RBM38 promoter activity significantly increased $(P<0.05$; Figure 2G). Meanwhile, knockdown of Snail in MDA-MB-231 cells raised RBM38 promoter luciferase as well $(P<0.05$; Figure $2 \mathrm{H})$. These evidences indicated that Snail directly repressed RBM38 expression by binding to E-box elements in its promoter region.
RBM38 overexpression counteracted cell migration and invasion induced by TGF- $\beta$ in breast cancer cells. To further investigate whether RBM38 took part in TGF- $\beta$-mediated cell migration and invasion, RBM38-overexpressed MCF7 cells and the control were exposed or not to TGF- $\beta$. We found that cell migration and invasion process induced by TGF- $\beta$ were distinctly attenuated via the overexpression of RBM38 (Figure 3A and B). Quantified data were the fold change of cell number with the exposure of TGF- $\beta$ divided by that with the control, indicating that TGF- $\beta$-mediated migration was dropped from 1.66 to 1.29 with RBM38 overexpression and the invasion was decreased from 2.10 to 1.61 with RBM38 overexpression.

RBM38 regulated the expression of $\mathrm{ZO}-1$ in breast cancer. In TGF- $\beta$-treated MCF7 cells, overexpression of RBM38 blocked the reduction of ZO-1 induced by TGF- $\beta$ (Figure $3 \mathrm{C}$ ). Similar result was obtained in BT474 cells (Figure 3D). Next, MCF7, BT474, and MDA-MB-231 cells were transfected with lentivirus to stably 
A

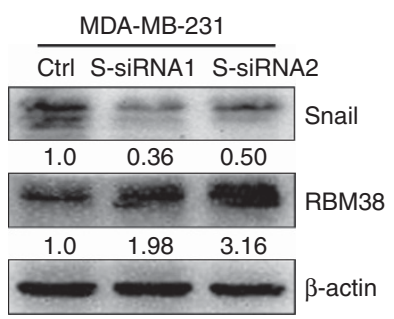

C

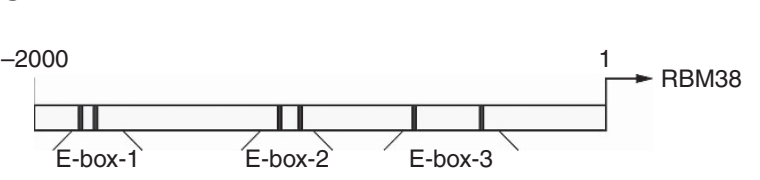

| E-box(5'-CANNTG-3')

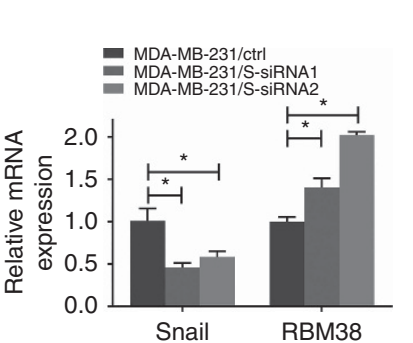

D

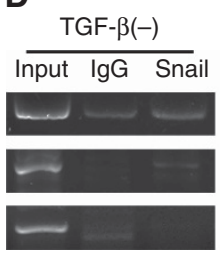

B
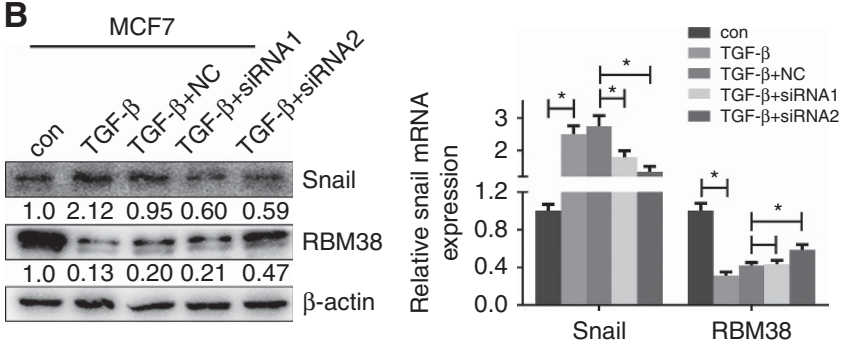

$\mathbf{F}$

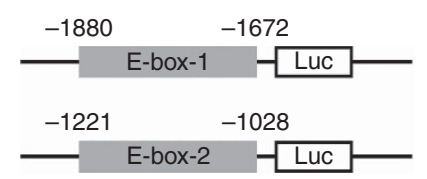

G

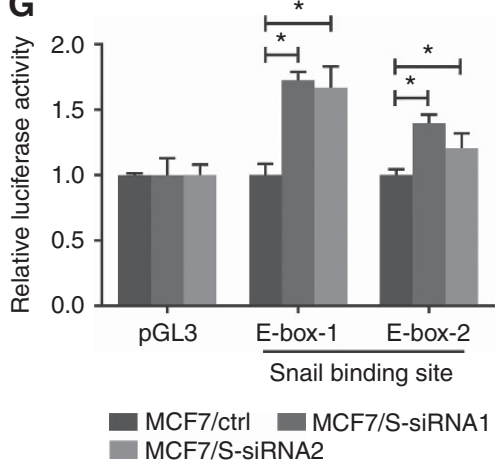

E

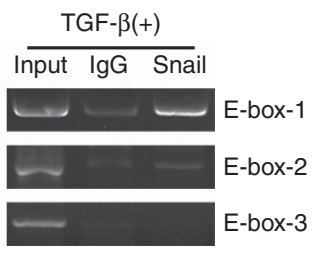

MDA-MB-231 Input IgG Snail

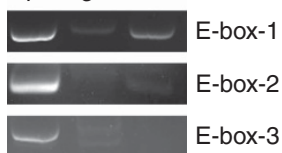

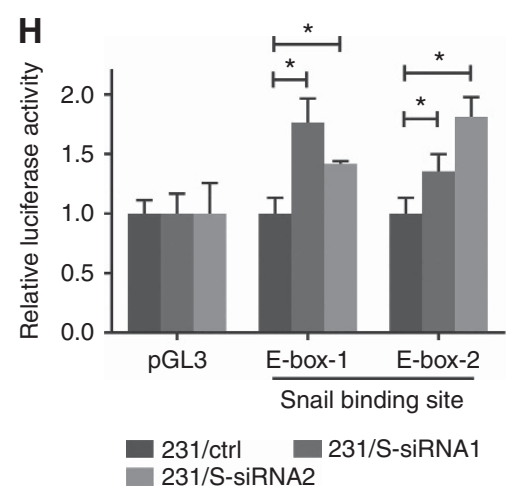

Figure 2. Repression of Snail restored RBM38 levels via binding to E-box in promoter region of RBM38 gene. (A) Expression of RBM38 was significantly increased after transfecting with siRNAs (S-siRNA1, S-siRNA2) to knock down the expression of Snail in MDA-MB-231 cells.

(B) Interference of Snail reversed TGF- $\beta$-stimulated downregulation of RBM38 expression in MCF7 cells. Western blot and qRT-PCR were applied to detect the expression of Snail and RBM38. The relative quantification was calculated by the $\Delta \Delta \mathrm{Ct}$ method and normalised based on $\beta$-actin. ${ }^{\star} P<0.05$. (C) Schematic diagram exhibiting six potential Snail-binding E-box elements in promoter region of RBM38 gene. (D) The ChIP analysis of regions E-box-1, -2 , and -3 was performed after treatment with or without TGF- $\beta 1\left(10 \mathrm{ng} \mathrm{ml}^{-1}\right)$ in MCF7 cells. With RBM38 promoter fragments, E-box-1 and E-box-2, Snail was detected brighter in TGF- $\beta$-stimulated cells than that without TGF- $\beta$. No difference was observed in E-box-3. (E) ChIP analysis was performed in MDA-MB-231 cells. A relatively brighter band was detected in Snail compared with the control IgG with E-box-1 and -2. No band was observed with E-box-3. (F) Schematic representation of the luciferase plasmid with E-box-1 and E-box-2 in promoter region of RBM38 gene. (G) The luciferase activity for the reporter carrying RBM38 E-box-1 and -2 was increased in TGF- $\beta$-treated MCF7 cells by knockdown of Snail. $(\mathrm{H})$ The luciferase activity for the reporter carrying RBM38 E-box-1 and -2 was increased by interfering with the level of Snail in MDA-MB231 cells (231). Data represented mean \pm s.d. of three independent experiments. ${ }^{\star} P<0.05$.

overexpress or knock down RBM38. The ZO-1 expression was increased in MCF7 cells alongside upregulation of RBM38 at both protein and mRNA levels $(P<0.05$; Figure $3 \mathrm{~A})$. Additionally, there was a significant decrease in $\mathrm{ZO}-1$ protein and transcript expression in RBM38-knockdown MCF7 cells $(P<0.05$; Figure $3 \mathrm{C})$. It indicated that RBM38 positively affected $\mathrm{ZO}-1$ expression in breast cancers cells. Similar results were observed in BT474 (Figure 3B and D) and MDA-MB-231 cells (Supplementary Figure S2A-D). These data suggested that RBM38 positively regulated $\mathrm{ZO}-1$ expression in breast cancer cells.

IHC staining of RBM38 and ZO-1 in human breast cancer tissues. To identify correlation of location and expression between RBM38 and ZO-1 in breast cancer tissues, IHC analysis was performed in 90 breast cancer tissues. Both RBM38 and ZO-1 were mainly expressed in the cytoplasm (Supplementary Figure S3A). The ZO-1 staining was obviously stronger in RBM38 highexpressed breast cancers compared with RBM38 low-expressed breast cancers $(P<0.05$; Supplementary Figure S3B). The correlation between RBM38 expression and clinicopathological features was analysed as shown in Supplementary Table 4. The RBM38 and
ZO-1 cellular localisation in breast cancer cells was confirmed using immunofluorescence (Supplementary Figure S4).

RBM38 enhanced ZO-1 mRNA stability in breast cancer. To further explore whether RBM38 promotes ZO-1 expression by regulating its mRNA stability, RBM38-overexpressed MCF7 and the control were treated with $5 \mu \mathrm{g} \mathrm{ml}^{-1}$ actinomycin-D (ActD), a transcription inhibitor, for various times. We found that overexpression of RBM38 prolonged the half-life of ZO-1 transcript from 2.1 to $4 \mathrm{~h}$ (Figure $4 \mathrm{~A}$ ). Knockdown of RBM38 shortened the half-life of ZO-1 transcript from 3.3 to $2 \mathrm{~h}$ (Figure 4C). Similar results were also found in BT474 cells (Figure 4B and D). These data indicated that RBM38 could increase ZO-1 mRNA stability.

RBM38 directly bound to the AREs in the ZO-1 mRNA $3^{\prime}$ UTR. To determine whether RBM38 physically binds to ZO-1 transcript, RNA immunoprecipitation assay was employed. The RBM38 antibody and control IgG were applied to immunoprecipitate RBM38-RNA complex in extracts from MCF7 cells. As Input, $10 \%$ of cell extracts were utilised. The ZO- 1 was detected in RBM38 rather than in the control IgG by RT-PCR (Figure 4E) and qRT-PCR (Figure 4F). Both HuR and p21 were detected as positive 
A

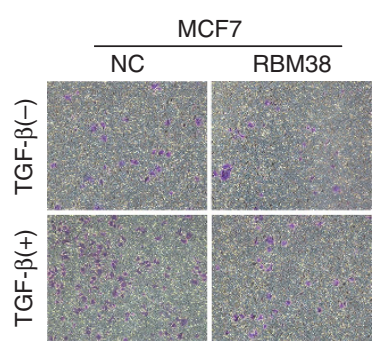

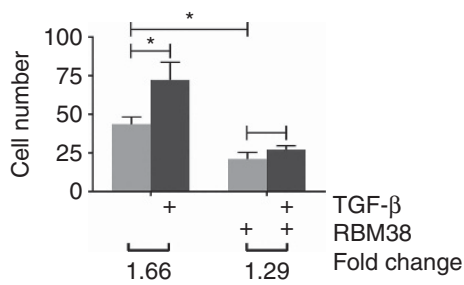

B
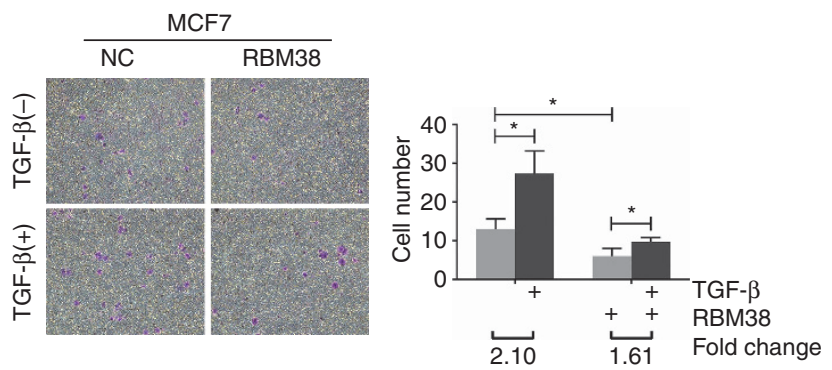

D

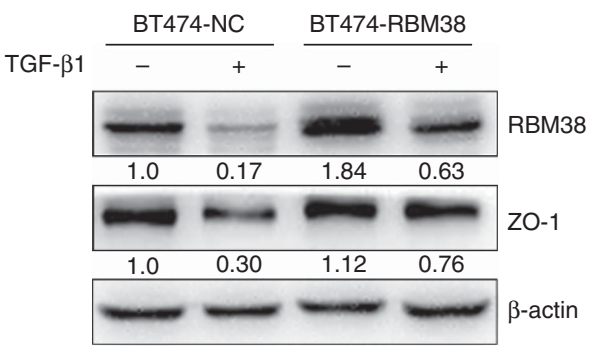

$\mathbf{F}$
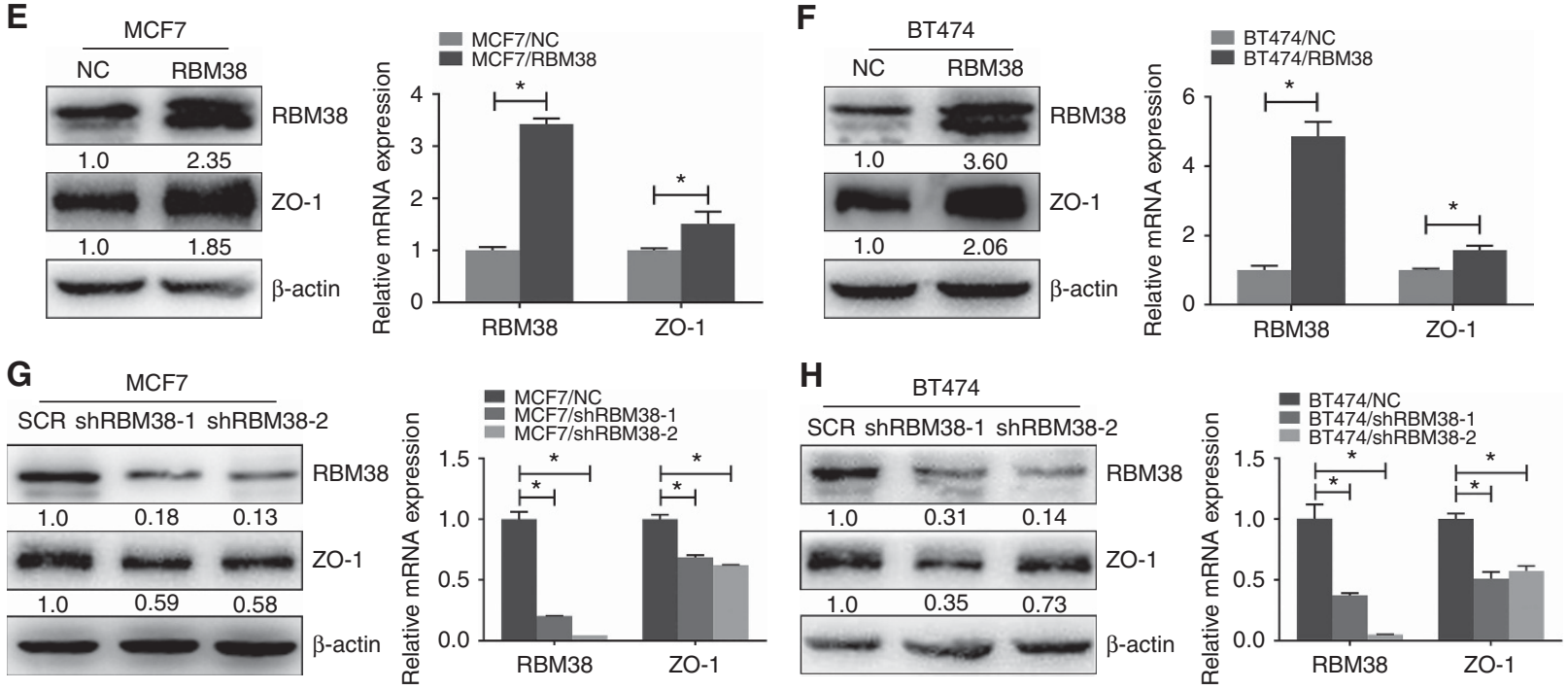

Figure 3. The RBM38 reinstated reduction of ZO-1 expression induced by TGF- $\beta$ and regulated ZO-1 gene and protein expression in breast cancer. The RBM38 counteracted the promotion of cell migration and invasion induced by TGF- $\beta$. (A and B) MCF7 cells that overexpress RBM38 and the control were exposed to TGF- $\beta$ or not. (A) Cell migration and (B) invasion assay were examined and representative images of migrated or invaded cells are shown. Right panel represents the migrating or invading cell numbers corresponding to the left panel. The assay was done in triplicate and presented as mean \pm s.d. ${ }^{*} P<0.05$. (C) MCF7 and (D) BT474 cells overexpressing RBM38 and the control were treated with or without TGF- $\beta 1\left(10 \mathrm{ng} \mathrm{ml}^{-1}\right)$. Reduction of ZO-1 expression induced by TGF- $\beta$ was blocked by upregulating RBM38. (E) The MCF7 and (F) BT474 cells were transfected with lentivirus to overexpress RBM38 (RBM38) and the control (NC). The ZO-1 expression was obviously increased after upregulating RBM38 at both protein and mRNA levels. (G) The MCF7 and (H) BT474 cells were transfected with the control (SCR) and RBM38 knockdown lentivirus (shRBM38-1, shRBM38-2). The ZO-1 level was distinctly decreased after downregulating RBM38 at both protein and mRNA levels. Western blot and QRT-PCR were applied to detect the expression of RBM38 and ZO-1. The relative quantification was calculated by the $\Delta \Delta \mathrm{Ct}$ method and normalised based on $\beta$-actin. Data were means of three separate experiments and presented as mean $\pm \mathrm{s}$.d. ${ }^{\star} P<0.05$.

controls, in accordance with the previous reports (Shu et al, 2006; Cho et al, 2010). No obvious $\beta$-actin band presented in either RBM38 or control IgG. Similarly, in BT474 cells, ZO-1, HuR, and p21 transcripts existed in RBM38 rather than in the control IgG (Figure $4 \mathrm{G}$ and $\mathrm{H}$ ). These results indicated that RBM38 could physically bind to ZO-1 mRNA.

Using bio-UTP-labelled probes (probes A, B, C, and D), REMSA was performed containing various fragments of $\mathrm{ZO}-1$ mRNA $3^{\prime}$-UTR (Figure 5A) to find out potential RBM38 binding site in ZO-1 mRNA. Bio-UTP-labelled p21 probe was utilised as a positive control. The RBM38 protein was able to form RNAprotein complexes (RPCs) with probe $\mathrm{B}$, but not probes $\mathrm{A}, \mathrm{C}$, and
D. Formation of the complex was weakened with the addition of p21 cold probe (Figure 5B).

To validate that AREs in ZO-1 mRNA $3^{\prime}$-UTR were required for $\mathrm{RBM} 38$ to promote ZO-1 expression, a dual-luciferase assay was performed using pGL3 control reporter or pGL3 reporters with ZO-1 $3^{\prime}$-UTR-A, -B, -C, and -D downstream, whose sequences were identical to probes $\mathrm{A}, \mathrm{B}, \mathrm{C}$, and $\mathrm{D}$, respectively (Figure $5 \mathrm{C}$ ). We found that the reporter carrying $3^{\prime}-\mathrm{UTR}-\mathrm{B}$ and $-\mathrm{D}$ exhibited a relatively stronger luciferase activity in RBM38-overexpressed MCF7 cells $(P<0.05$; Figure 5D). Although the luciferase activity for a reporter carrying fragment B or D in ZO-1 3'-UTR was obviously increased by RBM38, the REMSA assay for fragment $\mathrm{D}$ was not definite when $\mathrm{p} 21$ cold probe 

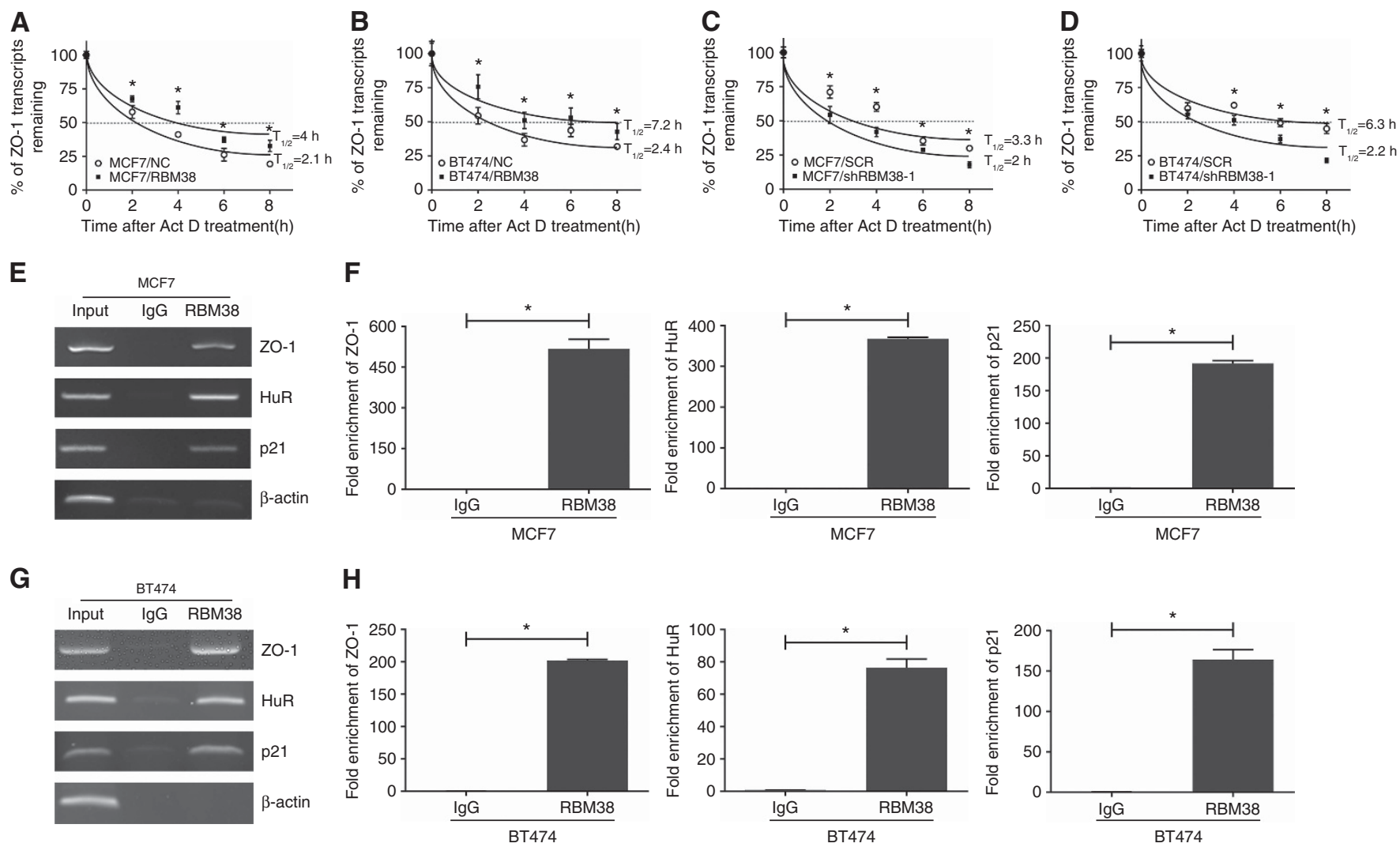

Figure 4. The RBM38 regulated ZO-1 mRNA stability by directly binding to its transcript. (A and B) Ectopic expression of RBM38 prolonged the half-life of ZO-1 transcript. (A) The MCF7 and (B) BT474 cells were transfected with lentivirus to overexpress RBM38. The RBM38 overexpression cells (RBM38) and the control (NC) were treated with $5 \mu \mathrm{g} \mathrm{ml}^{-1}$ actinomyclin D for 0, 2, 4, 6, and $8 \mathrm{~h}$. (C and D) Knockdown of RBM38 shortened the half-life of ZO-1 transcript. (C) The MCF7 and (D) BT474 cells were transfected with lentivirus to knock down the expression of RBM38 (shRBM38-1) and the control (SCR). The experiment was performed as described in RBM38 overexpression. Relative quantification was calculated by the $\Delta \Delta$ Ct method and normalised based on $\beta$-actin. ${ }^{*} P<0.05$. (E-H) The RBM38 associated with ZO-1 transcript in vivo. (E and $\left.\mathbf{F}\right)$ MCF-7 and ( $\mathbf{G}$ and $\mathbf{H}$ ) BT474 cell lysates were collected and immunoprecipitated with RBM38 antibody or control lgG followed by RT-PCR (E and G) and qRTPCR (F and $\mathbf{H})$ measuring transcript levels of ZO-1, HuR, and p21 in the control or RBM38-mRNA immunocomplexes. Upon normalisation of the level of $\beta$-actin transcript, the data were calculated from three separate experiments and performed as mean \pm s.d. ${ }^{\star} P<0.05$.

was added and not vice versa. Altogether, we concluded that ZO-1 $3^{\prime}$ UTR-B was the binding site of RBM38 in ZO-1 mRNA $3^{\prime}-$ UTR.

RBM38 overexpression rescued cell migration and invasion induced by knockdown of ZO-1. ZO-1 is proved to be a tumour suppressor in breast cancer, controlling endothelial cell-cell tension, cell migration, and barrier formation (Martin et al, 2004; Tornavaca et al, 2015). To examine the role of RBM38 on ZO-1-mediated cell migration and invasion, we silenced ZO-1 via transfecting with siRNAs, termed as Z-siRNA1 and Z-siRNA2, in MCF7 cell lines that expressed ectopic RBM38 and the control (Figure 6A). Then, Z-siRNA1 was selected for further study. Upon silencing of ZO-1 expression by Z-siRNA1, both RBM38-overexpression group and the control had stronger ability of migration and invasion. Moreover, by the overexpression of RBM38, MCF7 cell migration and invasion were evidently alleviated (Figure 6C and D). The fold change is the ratio of cell number with the transfection of Z-siRNA1 divided by that with the control, indicating that interfering of ZO-1-mediated migration was dropped from 1.98 to 1.43 with RBM38 overexpression. Furthermore, invasion was reduced from 2.57 to 1.79 with RBM38 overexpression. We obtained similar events in BT474 cells (Figure 6E and F). Cell migration was decreased from 1.76 to 1.20 with RBM38 overexpression. In addition, cell invasion was lessened from 2.03 to 1.69 with RBM38 overexpression. All the results suggested that overexpression of RBM38 had a stronger effect on inhibiting migration and invasion that would reverse the same biological process mediated by ZO-1 knockdown. To explore whether overexpression of ZO-1 counterbalanced silencing of RBM38 in vitro, we inversely transfected MCF7 and BT474 cells with vector encoding the ZO-1 (Supplementary Figure S5A-5C). However, the effect of ZO-1 on RBM38 mediated cell migration was not that clear (Supplementary Figure S5B-D).

\section{DISCUSSION}

In this study, we elucidated a new pathway of RBM38 involved in TGF- $\beta$-induced EMT. The RBM38 could stabilise ZO- 1 mRNA by directly binding to AREs in ZO-1 mRNA $3^{\prime}$-UTR and therefore inhibited cell migration and invasion. In addition, with active TGF$\beta$ signalling, RBM38 expression remarkably reduced that was directly regulated by transcription factor Snail targeting E-box elements in promoter region of RBM38 gene.

Our previous study demonstrated that RBM38 affected EMT process in breast cancer (Xue et al, 2014). Here, we identified a distinct reduction of RBM38 in mammary cells undergoing TGF$\beta$-mediated epithelial dedifferentiation. Meanwhile, the blockage of TGF- $\beta$ signalling by selective inhibitor SB431542 restored RBM38 expression levels, suggesting that RBM38 expression was modulated by TGF- $\beta$. Considering the importance of Snail in TGF- $\beta$ - 
A

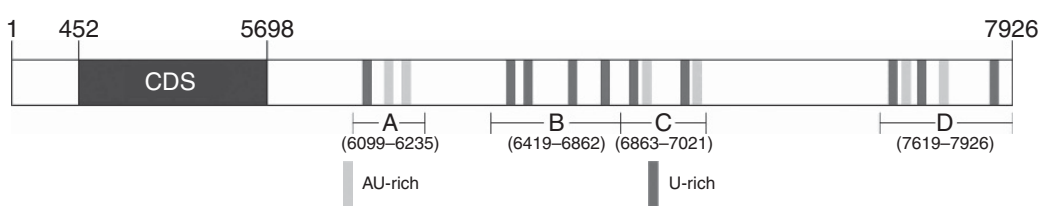

B
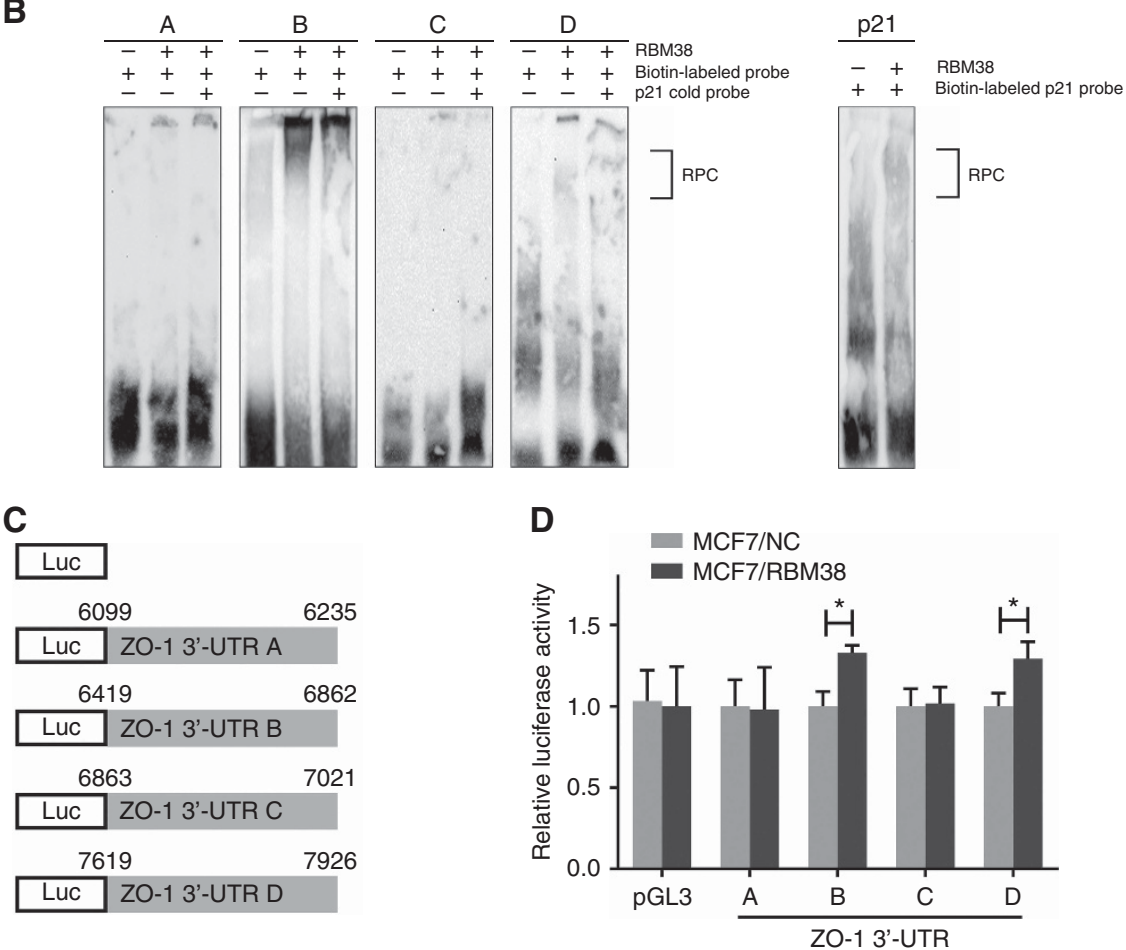

Figure 5. Multiple regions in the ZO-1 mRNA 3'-UTR were bound by RBM38. (A) Schematic representation of ZO-1 transcript and the location of probes used for REMSA. (B) Probes B and p21, but not probes A, C, and D, associated with RBM38. REMSA was performed by mixing bio-UTPlabelled probes A, B, C, D, or p21 with RBM38 protein, respectively. The bracket indicated RNA-protein complexes (RPCs). For a competition assay, an excess amount of p21 cold probe was added to the reaction mixture. (C) Schematic representation of the luciferase plasmid with various regions in ZO-1 mRNA 3'-UTR. (D) The luciferase activity for the reporter carrying ZO-1 3'-UTR-B, -D was increased by RBM38. The MCF7 cells with RBM38 overexpression lentivirus (RBM38) and the control (NC) were transfected with pGL3 control reporter or pGL3 reporter carrying various regions in 3'-UTR of ZO-1 mRNA for $48 \mathrm{~h}$, respectively. The fold increase in relative luciferase activity was a product of the luciferase activity induced by RBM38 divided by that induced by NC. Data represented mean \pm s.d. of three independent experiments. ${ }^{\star} P<0.05$.

induced EMT, the work was focussed on the relationship between Snail and RBM38. By interfering the expression of Snail, RBM38 level was accumulated. Furthermore, as six E-box elements, the Snail recognising sequences, exist in RBM38 promoter region, the ChIP assay and dual-luciferase reporter assay were conducted and proved that Snail bound to E-box-1 and E-box-2 in promoter region of RBM38 gene and therefore restrained the RBM38 expression.

With the enhanced expression of Snail induced by TGF- $\beta$, TJ proteins, including claudin-1, occludin, and $\mathrm{ZO}-1$, were downregulated (Ohkubo and Ozawa, 2004; Li et al, 2011). Additionally, Zhang et al (2013b) reported that the Rho/ROCK signalling pathway mediated by TGF- $\beta$ played a role in the dissolution of TJs during EMT. Here we found that enhanced expression of RBM38 prevented the loss of ZO-1 expression stimulated by TGF- $\beta$, indicating that ZO-1 might be the downstream of RBM38. We further investigated a significant correlation between RBM38 and ZO-1 expression in breast cancer cells. Overexpression of RBM38 increased ZO-1 expression, whereas RBM38 knockdown decreased ZO-1 expression. The RBM38 was able to increase ZO-1 mRNA stability by prolonging its half-life, whereas RBM38 knockdown obviously decreased the stability of ZO-1 transcript. We further confirmed that RBM 38 could bind to ZO-1 transcript directly by
RIP assay. Previous studies found that RBM38 bound to mRNA 3'UTR of many target genes and altered the stability of the transcripts that all contain multiple AREs (Zhang et al, 2010, 2013a; Yin et al, 2013; Cho et al, 2015; Li et al, 2017). Consistent with this, ZO-1 mRNA 3'-UTR contains several AREs that can be bound by RBPs (Chen et al, 2008; Nagaoka et al, 2012). Our results indicated that RBM38 directly bound to fragment $\mathrm{B}$ in $\mathrm{ZO}-1$ mRNA $3^{\prime}$-UTR. Binding of ZO-1 AREs within its $3^{\prime}$-UTR by RBM38 led to enhanced stability of ZO-1 transcript. Here we uncovered a novel mechanism that RBM38 is a positive posttranscriptional regulator of ZO-1 in breast cancer.

Accordingly, TJs in epithelial cells function in an adhesive manner and prevent cell dissociation, being the first barrier that cancer cells must overcome for metastasis (Martin and Jiang, 2009). As a member of the $\mathrm{ZO}$ family, $\mathrm{ZO}-1$ contains multiple domains with numerous binding partners (Fanning and Anderson, 2009) that controls endothelial cell-cell tension, cell migration, angiogenesis, and barrier formation (Tornavaca et al, 2015). Here we demonstrated that the cell migration and invasion progression caused by the loss of ZO-1 was rescued by upregulation of RBM38. However, it is not obvious that ZO-1 counterbalances silencing of RBM38 in vitro. Altogether, we proposed that under stimulation of TGF- $\beta, \quad$ RBM38 was downregulated through transcription 

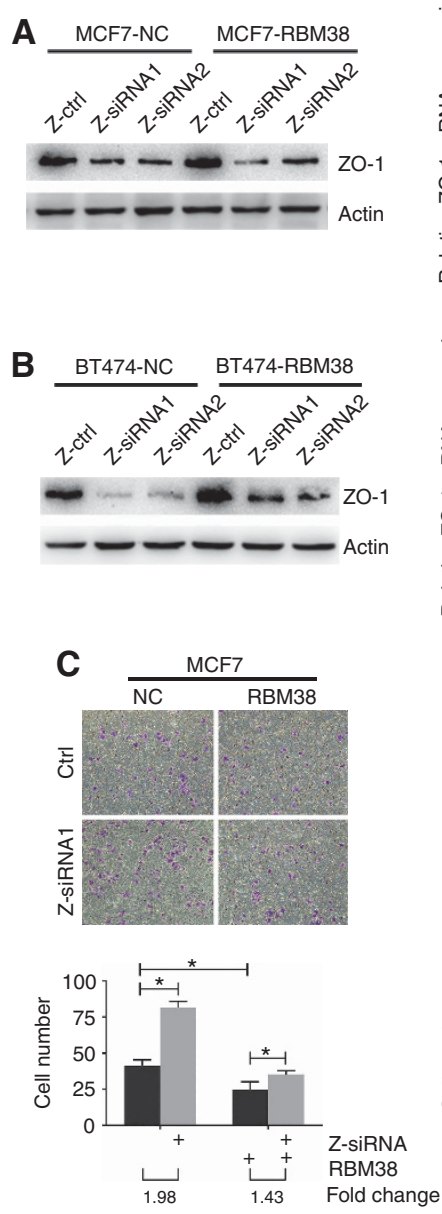
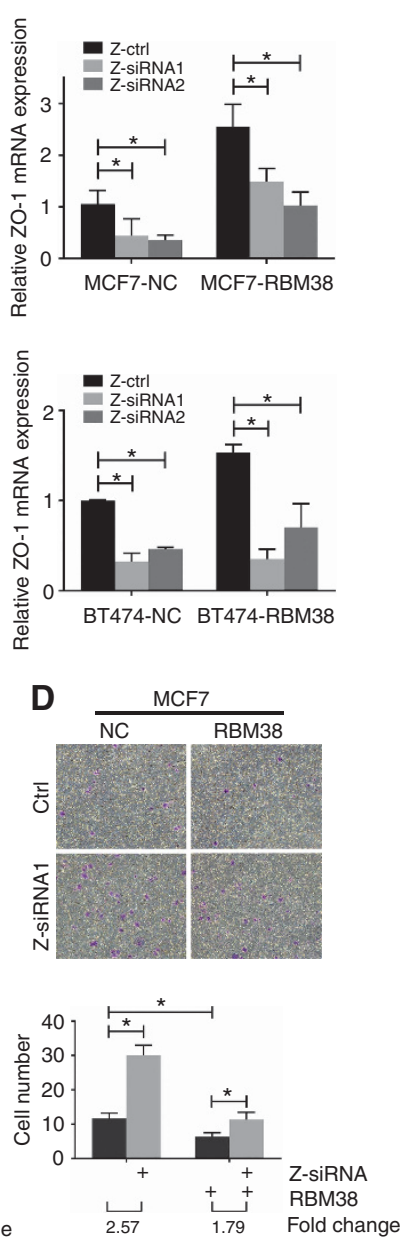
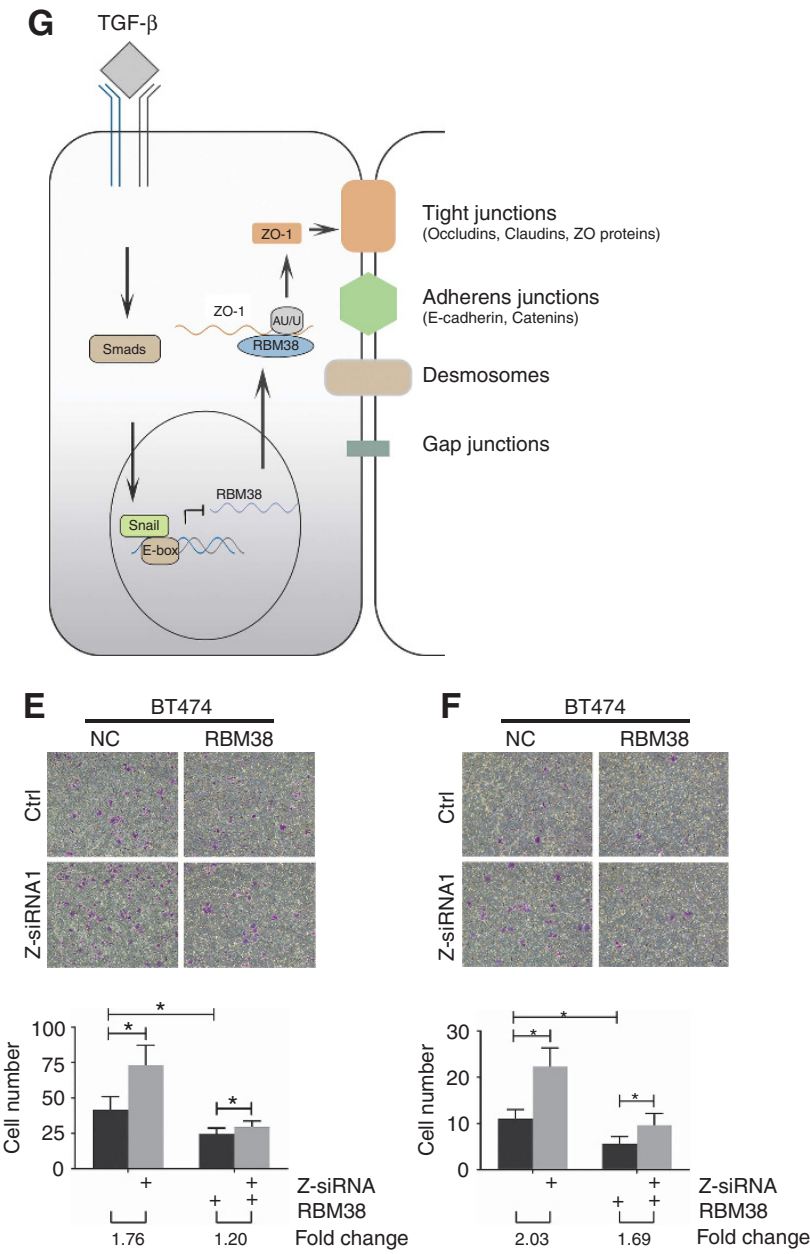

Figure 6. The RBM38 rescued the enhancement of cell migration and invasion induced by knockdown of ZO-1. (A) The MCF7 and (B) BT474 cells were transfected with siRNAs to silence ZO-1 expression in both RBM38-overexpressed cells and the control. Cell lysates were collected and analysed by western blotting and qRT-PCR. (C-F) The RBM38 rescued the promotion of cell migration and invasion induced by knockdown of ZO-1. (C) Cell migration and (D) cell invasion assay were performed using the cells treated as in (A). Lower panel represents the migrating and invading cell numbers corresponding to the upper panel. (E) Cell migration and (F) cell invasion assay were performed in BT474 cells and analysed as in ( $\mathbf{C}$ and $\mathbf{D})$. The assay was done in triplicate and a representative image is shown. ${ }^{\star} P<0.05$. (G) A model for the new pathway of RBM38 involved in TGF- $\beta$-induced EMT in breast cancer.

suppressor Snail, and low level of RBM38 led to decreased expression of ZO-1, and then contributed to cell invasion and migration (Figure 6G).

Considering the fact that TGF- $\beta$ activates various signalling pathways, and the interactions among these pathways are quite complex (Gonzalez and Medici, 2014), the mechanism through which TGF- $\beta$ controls the expression of RBM38 requires further investigation. Furthermore, more researches are required to clarify RBM38 regulation networks so as to explore the utility of RBM38 as a biomarker for breast cancer diagnosis and prognosis.

\section{ACKNOWLEDGEMENTS}

This work was supported by the Nature Science Foundation of China $(81572595,81602336,81202077)$ and the Key Medical Subjects of Jiangsu Province (H201110 to QD).

\section{CONFLICT OF INTEREST}

The authors declare no conflict of interest.

\section{REFERENCES}

Batlle E, Sancho E, Franci C, Dominguez D, Monfar M, Baulida J, Garcia De Herreros A (2000) The transcription factor snail is a repressor of E-cadherin gene expression in epithelial tumour cells. Nat Cell Biol 2: 84-89.

Bolos V, Peinado H, Perez-Moreno MA, Fraga MF, Esteller M, Cano A (2003) The transcription factor Slug represses E-cadherin expression and induces epithelial to mesenchymal transitions: a comparison with Snail and E47 repressors. J Cell Sci 116: 499-511.

Brysse A, Mestdagt M, Polette M, Luczka E, Hunziker W, Noel A, Birembaut P, Foidart JM, Gilles C (2012) Regulation of CXCL8/IL-8 expression by zonula occludens-1 in human breast cancer cells. Mol Cancer Res 10: 121-132.

Chen J, Xiao L, Rao JN, Zou T, Liu L, Bellavance E, Gorospe M, Wang JY (2008) JunD represses transcription and translation of the tight junction protein zona occludens-1 modulating intestinal epithelial barrier function. Mol Biol Cell 19: 3701-3712.

Chen W, Zheng R, Baade PD, Zhang S, Zeng H, Bray F, Jemal A, Yu XQ, He J (2016) Cancer statistics in China, 2015. CA Cancer J Clin 66: 115-132.

Cho SJ, Jung YS, Zhang J, Chen X (2012) The RNA-binding protein RNPC1 stabilizes the mRNA encoding the RNA-binding protein HuR and cooperates with HuR to suppress cell proliferation. J Biol Chem 287: 14535-14544. 
Cho SJ, Teng IF, Zhang M, Yin T, Jung YS, Zhang J, Chen X (2015) Hypoxiainducible factor 1 alpha is regulated by RBM38, a RNA-binding protein and a p53 family target, via mRNA translation. Oncotarget 6: 305-316.

Cho SJ, Zhang J, Chen X (2010) RNPC1 modulates the RNA-binding activity of, and cooperates with, HuR to regulate p21 mRNA stability. Nucleic Acids Res 38: 2256-2267.

Dong C, Wu Y, Yao J, Wang Y, Yu Y, Rychahou PG, Evers BM, Zhou BP (2012) G9a interacts with Snail and is critical for Snail-mediated E-cadherin repression in human breast cancer. J Clin Invest 122: 1469-1486.

Fanning AS, Anderson JM (2009) Zonula occludens-1 and -2 are cytosolic scaffolds that regulate the assembly of cellular junctions. Ann NY Acad Sci 1165: $113-120$.

Fischer KR, Durrans A, Lee S, Sheng J, Li F, Wong ST, Choi H, El Rayes T, Ryu S, Troeger J, Schwabe RF, Vahdat LT, Altorki NK, Mittal V, Gao D (2015) Epithelial-to-mesenchymal transition is not required for lung metastasis but contributes to chemoresistance. Nature 527: 472-476.

Fransvea E, Angelotti U, Antonaci S, Giannelli G (2008) Blocking transforming growth factor-beta up-regulates E-cadherin and reduces migration and invasion of hepatocellular carcinoma cells. Hepatology 47: 1557-1566.

Gonzalez DM, Medici D (2014) Signaling mechanisms of the epithelialmesenchymal transition. Sci Signal 7: re8.

Itoh M, Bissell MJ (2003) The organization of tight junctions in epithelia: implications for mammary gland biology and breast tumorigenesis J Mammary Gland Biol Neoplasia 8: 449-462.

Kalluri R, Weinberg RA (2009) The basics of epithelial-mesenchymal transition. J Clin Invest 119: 1420-1428.

Keene JD (2007) RNA regulons: coordination of post-transcriptional events. Nat Rev Genet 8: 533-543.

Lamouille S, Xu J, Derynck R (2014) Molecular mechanisms of epithelialmesenchymal transition. Nat Rev Mol Cell Biol 15: 178-196.

Li H, Wang H, Wang F, Gu Q, Xu X (2011) Snail involves in the transforming growth factor beta1-mediated epithelial-mesenchymal transition of retinal pigment epithelial cells. PLoS ONE 6: e23322.

Li W, Kang Y (2016) Probing the fifty shades of EMT in metastasis. Trends Cancer 2: 65-67.

Li XX, Shi L, Zhou XJ, Wu J, Xia TS, Zhou WB, Sun X, Zhu L, Wei JF, Ding Q (2017) The role of c-Myc-RBM38 loop in the growth suppression in breast cancer. J Exp Clin Cancer Res 36: 49.

Lou P, Li C, Shi L, Xia TS, Zhou W, Wu J, Zhou X, Li X, Wang Y, Wei JF, Ding Q (2017) RNPC1 enhances progesterone receptor functions by regulating its mRNA stability in breast cancer. Oncotarget 8: 16387-16400,

Martin TA, Jiang WG (2009) Loss of tight junction barrier function and its role in cancer metastasis. Biochim Biophys Acta 1788: 872-891.

Martin TA, Watkins G, Mansel RE, Jiang WG (2004) Loss of tight junction plaque molecules in breast cancer tissues is associated with a poor prognosis in patients with breast cancer. Eur J Cancer 40: 2717-2725.

Miettinen PJ, Ebner R, Lopez AR, Derynck R (1994) TGF-beta induced transdifferentiation of mammary epithelial cells to mesenchymal cells: involvement of type I receptors. J Cell Biol 127: 2021-2036.

Nagaoka K, Udagawa T, Richter JD (2012) CPEB mediated ZO-1 mRNA localization is required for epithelial tight junction assembly and cell polarity. Nat Commun 3: 675.

Nieto MA (2002) The snail superfamily of zinc-finger transcription factors. Nat Rev Mol Cell Biol 3: 155-166.

Nieto MA, Huang RY, Jackson RA, Thiery JP (2016) Emt: 2016. Cell 166: 21-45.

Ohkubo T, Ozawa M (2004) The transcription factor Snail downregulates the tight junction components independently of E-cadherin downregulation. J Cell Sci 117: 1675-1685.

Padua D, Massague J (2009) Roles of TGFbeta in metastasis. Cell Res 19: 89-102.

Park YM, Lee YH, Kim SH, Lee EY, Kim KS, Williams DR, Lee HC (2012) Snail, a transcriptional regulator, represses adiponectin expression by directly binding to an E-box motif in the promoter. Metabolism 61: 1622-1632.

Shi L, Xia TS, Wei XL, Zhou W, Xue J, Cheng L, Lou P, Li C, Wang Y, Wei JF, Ding Q (2015) Estrogen receptor (ER) was regulated by RNPC1 stabilizing mRNA in ER positive breast cancer. Oncotarget 6: 12264-12278.

Shi Y, Massague J (2003) Mechanisms of TGF-beta signaling from cell membrane to the nucleus. Cell 113: 685-700.

Shu L, Yan W, Chen X (2006) RNPC1, an RNA-binding protein and a target of the p53 family, is required for maintaining the stability of the basal and stress-induced p21 transcript. Genes Dev 20: 2961-2972.
Siegel RL, Miller KD, Jemal A (2016) Cancer statistics, 2016. CA Cancer J Clin 66: 7-30.

Taipaleenmaki H, Harkness L, Chen L, Larsen KH, Saamanen AM, Kassem M, Abdallah BM (2012) The crosstalk between transforming growth factorbeta1 and delta like-1 mediates early chondrogenesis during embryonic endochondral ossification. Stem Cells 30: 304-313.

Takano S, Kanai F, Jazag A, Ijichi H, Yao J, Ogawa H, Enomoto N, Omata M, Nakao A (2007) Smad4 is essential for down-regulation of E-cadherin induced by TGF-beta in pancreatic cancer cell line PANC-1. J Biochem 141: $345-351$

Thiery JP, Acloque H, Huang RY, Nieto MA (2009) Epithelial-mesenchymal transitions in development and disease. Cell 139: 871-890.

Thiery JP, Sleeman JP (2006) Complex networks orchestrate epithelialmesenchymal transitions. Nat Rev Mol Cell Biol 7: 131-142.

Tian YC, Phillips AO (2002) Interaction between the transforming growth factor-beta type II receptor/Smad pathway and beta-catenin during transforming growth factor-beta1-mediated adherens junction disassembly. Am J Pathol 160: 1619-1628.

Tornavaca O, Chia M, Dufton N, Almagro LO, Conway DE, Randi AM, Schwartz MA, Matter K, Balda MS (2015) ZO-1 controls endothelial adherens junctions, cell-cell tension, angiogenesis, and barrier formation. J Cell Biol 208: 821-838.

Wang Y, Shi J, Chai K, Ying X, Zhou BP (2013) The role of Snail in EMT and tumorigenesis. Curr Cancer Drug Targets 13: 963-972.

Xiao L, Wang JY (2014) RNA-binding proteins and microRNAs in gastrointestinal epithelial homeostasis and diseases. Curr Opin Pharmacol 19: $46-53$.

Xu E, Zhang J, Chen X (2013) MDM2 expression is repressed by the RNA-binding protein RNPC1 via mRNA stability. Oncogene 32: 2169-2178.

Xu J, Lamouille S, Derynck R (2009) TGF-beta-induced epithelial to mesenchymal transition. Cell Res 19: 156-172.

Xue JQ, Xia TS, Liang XQ, Zhou W, Cheng L, Shi L, Wang Y, Ding Q (2014) RNA-binding protein RNPC1: acting as a tumor suppressor in breast cancer. BMC Cancer 14: 322.

Yan W, Zhang J, Zhang Y, Jung YS, Chen X (2012) p73 expression is regulated by RNPC1, a target of the p53 family, via mRNA stability. Mol Cell Biol 32: 2336-2348.

Yang H, Rao JN, Wang JY (2014) Posttranscriptional regulation of intestinal epithelial tight junction barrier by RNA-binding proteins and microRNAs. Tissue Barriers 2: e28320.

Yin T, Cho SJ, Chen X (2013) RNPC1, an RNA-binding protein and a p53 target, regulates macrophage inhibitory cytokine-1 (MIC-1) expression through mRNA stability. J Biol Chem 288: 23680-23686.

Yu H, Shen Y, Hong J, Xia Q, Zhou F, Liu X (2015) The contribution of TGF-beta in epithelial-mesenchymal transition (EMT): down-regulation of E-cadherin via snail. Neoplasma 62: 1-15.

Yu TX, Wang PY, Rao JN, Zou T, Liu L, Xiao L, Gorospe M, Wang JY (2011) Chk2-dependent HuR phosphorylation regulates occludin mRNA translation and epithelial barrier function. Nucleic Acids Res 39: 8472-8487.

Zhang J, Jun Cho S, Chen X (2010) RNPC1, an RNA-binding protein and a target of the p53 family, regulates p63 expression through mRNA stability. Proc Natl Acad Sci USA 107: 9614-9619.

Zhang J, Xu E, Chen X (2013a) Regulation of Mdm2 mRNA stability by RNAbinding protein RNPC1. Oncotarget 4: 1121-1122.

Zhang K, Zhang H, Xiang H, Liu J, Liu Y, Zhang X, Wang J, Tang Y (2013b) TGF-betal induces the dissolution of tight junctions in human renal proximal tubular cells: role of the RhoA/ROCK signaling pathway. Int $J$ Mol Med 32: 464-468.

Zheng X, Carstens JL, Kim J, Scheible M, Kaye J, Sugimoto H, Wu CC, Lebleu VS, Kalluri R (2015) Epithelial-to-mesenchymal transition is dispensable for metastasis but induces chemoresistance in pancreatic cancer. Nature 527: 525-530.

This work is published under the standard license to publish agreement. After 12 months the work will become freely available and the license terms will switch to a Creative Commons AttributionNonCommercial-Share Alike 4.0 Unported License.

Supplementary Information accompanies this paper on British Journal of Cancer website (http://www.nature.com/bjc) 